\title{
Molduras do protesto: debates e desafios da abordagem do enquadramento interpretativo no estudo de movimentos sociais
}

\author{
Matheus Mazzilli Pereira
}

\section{Resumo}

Este ensaio bibliográfico tem como intuito apresentar os principais debates estabelecidos na perspectiva do enquadramento interpretativo aplicada ao estudo de movimentos sociais, tendo em vista que as pesquisas brasileiras inseridas nesse campo de estudo dirigem apenas recentemente sua atenção a essa abordagem já consagrada em outros países. Para isso, é realizada uma análise da coletânea de artigos editada por Hank Johnston e John A. Noakes, intitulada Frames of protest (Molduras de protesto). Esse livro reúne trabalhos que trazem contribuições teóricas importantes para os debates já estabelecidos nesse campo de estudos. Os estudos apresentados nessa coletânea, no entanto, abrem novas perguntas a serem respondidas e se mostram insuficientes para superar os principais problemas de indefinição conceitual e de fragilidade metodológica enfrentados por essa abordagem.

Palauras-chave: Sociologia da ação coletiva. Enquadramento interpretativo. Molduras interpretativas da ação coletiva.

Aplicado à análise de movimentos sociais desde a década de 1980 por teóricos como William Gamson, Robert Benford e David Snow, ${ }^{2}$ o conceito de "moldura interpretativa da açáo coletiva" (Miac) se fortaleceu no cenário internacional a partir da década de 1990, ao ser assimilado pelos esquemas

Doutorando em Sociologia pela Universidade Federal do Rio Grande do Sul (UFRGS), Porto Alegre, Rio Grande do Sul, Brasil. Membro do Grupo de Pesquisa Associativismo. Contestação e Engajamento, vinculado ao Programa de Pós-Graduação em Sociologia (PPGS) da UFRGS. E-mail: matheus.mazzilli@gmail.com.

2 Como trabalhos pioneiros na aplicação do conceito de "enquadramento interpretativo" à análise de problemas relacionados à ação coletiva, podem ser citados os estudos de Camson, Fireman e Rytina (1992) e de Snow et al. (1986) 
teóricos norte-americanos da teoria do processo político (TPP) que buscavam fortalecer sua compreensão dos fenômenos simbólicos e culturais ligados à açáo coletiva (MCADAM; MCCARTHY; ZALD, 1999; TARROW, 2009). Segundo Goffman (1986, p. 10, traduçáo livre), molduras interpretativas são "princípios de organizaçáo que governam eventos [...] e nosso envolvimento subjetivo neles". Tendo como base essa definiçấo, os teóricos da açáo coletiva Benford e Snow (2000, p. 614, traduçáo livre) propóem o conceito de Miac, sendo definido como um tipo de moldura interpretativa que teria como objetivo "mobilizar potenciais aderentes e constituintes, conquistar o suporte dos espectadores e desmobilizar antagonistas", inspirando e legitimando as atividades de um movimento social.

No Brasil, no entanto, a abordagem da TPP como um todo e, particularmente, o conceito de Miac começam a conquistar espaço no campo de estudos de movimentos sociais apenas nos últimos anos (SILVA, 2010). Assim, se ao longo da década de 2000, no contexto internacional, estudiosos do assunto se dedicaram ao trabalho de revisão bibliográfica do uso desse conceito, essa discussão não se fez presente com força na literatura brasileira. ${ }^{3}$ Nesse contexto, este ensaio bibliográfico baseado na coletânea de artigos Frames of protest, organizada por Johnston e Noakes (2005), tem como intuito apresentar ao debate nacional as mais importantes discussóes estabelecidas em torno do conceito de Miac, focando-se nas principais contribuiçóes desses artigos para essas discussóes, assim como nas dificuldades náo superadas por essa coletânea.

O livro Frames of protest apresenta uma sistematização da discussão até entáo acumulada em torno de diversos debates existentes dentro dessa perspectiva e, ao mesmo tempo, apresenta estudos que contribuem com novas proposiçóes teóricas para esses debates. O seu capítulo introdutório, escrito por Johnston e Noakes (2005), propóe uma revisão bibliográfica e um mapeamento dos debates construídos em torno desse conceito. A seguir, a primeira parte do livro é constituída por três artigos que apresentam estudos empíricos sobre enquadramento interpretativo em processos de mobilizaçáo coletiva, abordando problemas teóricos diversos, tais como a ressonância de molduras

3 Como exemplos de estudos brasileiros que aplicam o conceito de "molduras interpretativas" à análise de problemas relacionados à ação coletiva ou que o aplicam a discussões teóricas relacionadas a esse tema podem ser citados os trabalhos de Bertoncelo (2009), Maciel (2011), Mendonça e Simões (2012) e Prudencio e Santos (2011). 
contestadoras (HEWIT; McCAMMON, 2005), a construção dessas interpretaçóes (VALOCCHI, 2005) e a relação entre enquadramento interpretativo e emoçóes (CADENA-ROA, 2005). A segunda parte do livro se dedica a estudos empíricos focados em processos de enquadramento interpretativo conduzidos por outros atores que náo movimentos sociais inseridos em confrontos políticos, tais como o Estado (NOAKES, 2005) e a grande mídia (WALGRAVE; MANSSENS, 2005). A terceira parte do livro tem como foco a problemática da relaçáo entre enquadramento interpretativo e um conceito central da TPP, o de estrutura de oportunidades políticas (EOP) (KENNEY, 2005; SCHNEIDER, 2005). Por fim, a última parte da coletânea inclui artigos teóricos que versam sobre problemas de definição conceitual existentes nessa perspectiva (OLIVER; JOHNSTON, 2005; SNOW; BENFORD, 2005; WESTBY, 2005) e sobre questóes metodológicas (JOHNSTON, 2005).

A introdução da coletânea analisada, escrita por seus organizadores, consiste em uma revisáo bibliográfica muito semelhante àquela proposta por Benford e Snow (2000) em um artigo cinco anos antes da publicação do livro em análise. Nessa introduçáo, a agenda de pesquisa dessa abordagem é dividida em cinco grandes debates: as tarefas nucleares de enquadramento; a construçáo de Miacs; a ressonância do enquadramento; a disputa pela supremacia cultural; e a relaçáo entre enquadramento interpretativo e oportunidades políticas.

No que tange ao primeiro desses temas, as duas revisóes teóricas citadas praticamente não se diferenciam. Os autores centram sua exposição em torno das três tarefas de enquadramento interpretativo já estabelecidas por Benford e Snow (2000): o diagnóstico, o prognóstico e a motivação. Nenhum dos artigos posteriormente apresentados no livro, no entanto, apresenta maiores contribuiçóes teóricas para a análise dessa questáo. Nesse sentido, nessa coletânea não são debatidos os limites e as potencialidades dessa tipologia ou propostas novas formas de classificaçáo dos componentes das Miacs, como, posteriormente, fazem Johnston e Alimi $(2012,2013)$ por meio de sua análise do "sujeito", do "verbo" e do "objeto" das molduras interpretativas.

Inserindo-se no debate sobre a ressonância do enquadramento, ${ }^{4}$ as discussóes expostas nessa coletânea apresentam importantes desenvolvimentos teóricos.

4 Como exemplos de outros estudos relacionados a esse debate, podem ser citados os trabalhos de Babb (1996), Diani (1996), McAdam (1999) e Snow e Benford (1988). 
Uma Miac é ressonante quando os alvos do enquadramento consideram a interpretaçáo proposta pelos movimentos sociais relevante para a classificaçáo das situaçóes por eles vivenciadas. Pode ser observada uma tese central que guia a literatura acerca dessa discussáo: a de que, quanto maior a proximidade entre as mensagens transmitidas pelos movimentos sociais em relaçáo aos conceitos já estabelecidos culturalmente, maior será a ressonância do enquadramento dos ativistas (NOAKES; JOHNSTON, 2005). Ao analisar comparativamente a capacidade de recrutamento de três organizaçóes norte-americanas de defesa do sufrágio feminino que utilizavam distintas Miacs entre os anos de 1982 e 1919, Hewitt e McCammon (2005) se opóem a essa tese. Os dados por elas produzidos apontam que o maior sucesso em atividades de recrutamento não foi obtido pela organizaçáo cujas mensagens se aproximavam mais da cultura vigente, mas pela organização que fornecia equilíbrio entre símbolos culturalmente estabelecidos e mensagens contestatórias. ${ }^{5}$

Ao delimitar as conclusóes de seu estudo, as autoras fazem uma ressalva importante. $\mathrm{O}$ estudo proposto se dedica apenas ao potencial de recrutamento das Miacs. Seria necessário, portanto, que análises semelhantes fossem realizadas tendo-se como referentes outros objetivos que movimentos sociais possam buscar por meio da ressonância de suas molduras em seus interlocutores (HEWITT; MACCAMMON, 2005). Destaca-se a importância dessa ressalva, na medida em que teóricos dessa abordagem parecem reduzir os objetivos dos processos de enquadramento interpretativo às dinâmicas de recrutamento, mobilização de ativistas e desmobilizaçáo de adversários. ${ }^{6}$ Considera-se importante, portanto, que se questione teoricamente se esses são os únicos objetivos possíveis das atividades de um movimento social. Acredita-se que tanto a aproximaçáo defendida pelas autoras entre essa literatura e discussóes teóricas acerca dos outputs dos movimentos sociais (GIUGNI; MCADAM; TILLY, 1999) quanto um diálogo entre a abordagem do enquadramento interpretativo e debates que se detenham sobre as diversas lógicas existentes nos processos de mobilização coletiva (AUYERO, 2011; QUIRÓS, 2009) podem produzir reflexóes teóricas significativas não desenvolvidas em profundidade nessa coletânea.

5 Além do balanço entre elementos conservadores e elementos opositores, duas outras caracteristicas das molduras são apontadas como relevantes para a produção de recrutamento: a neutralização e o escopo (HEWITT; MCCAMMON, 2005)

6 Isso pode ser observado na própria definição do conceito. 
O terceiro dos debates citados pelos autores se refere à disputa pela supremacia cultural, problema análogo ao analisado por Benford e Snow (2000) por meio de seu conceito de "processos contestados de enquadramento". Essa temática dialoga com uma tendência contemporânea da literatura da açáo coletiva, situando as atividades dos movimentos sociais em um campo complexo de relaçóes entre diversos atores. Dessa forma, o enquadramento interpretativo fornecido por movimentos sociais deve ter uma dimensão de "tréplica" a respostas de adversários. Dois artigos incluídos nesse livro, no entanto, desfiam a ideia de que atores como a mídia e o Estado agem apenas em "resposta" aos desafios culturais propostos pelos movimentos sociais, sendo também eles concebidos como atores capazes de construir mensagens que incentivem a ação coletiva.

No que tange à mídia de massa, Walgrave e Manssens (2005) argumentam que, mais do que apenas reproduzir e discutir interpretaçóes existentes, a grande mídia é capaz de construir suas próprias molduras interpretativas que difundam determinadas manifestaçóes de massa. Assim, os autores sustentam que a grande mídia impressa belga foi responsável pela mobilização da "Marcha Branca", que reuniu milhares de cidadãos desse país em torno de duas principais demandas: a puniçáo de um réu suspeito de assassinar quatro garotas; e a aproximação entre as instituiçóes políticas e a população. Noakes (2005) constrói um argumento semelhante ao defender que o Escritório Federal de Investigaçóes (FBI) do governo norte-americano foi responsável pela criaçáo de uma moldura que defendia que determinados atores e roteiristas da grande indústria cinematográfica dos Estados Unidos procuravam transmitir mensagens anticapitalistas em suas produçóes. O FBI, no entanto, teria desistido de promover ele mesmo essa interpretação, utilizando um órgáo do Poder Legislativo para cumprir essa tarefa. Tal decisão teria sido tomada devido às características institucionais desses dois órgáos de Estado. Por se dedicar a investigaçóes criminais, ao apresentar essas interpretaçóes, caberia ao FBI o ônus da prova. Se esse órgáo náo apresentasse elementos convincentes para que a populaçáo considerasse comprovada a existência de tal ameaça, ele poderia perder sua legitimidade. Já o órgáo legislativo náo precisaria divulgar provas concretas para manter sua legitimidade. Assim, o estudo critica a tese de que a ressonância das molduras seria determinada apenas pelas suas características simbólicas, sendo necessário analisar o impacto que o papel institucional dos 
promotores das molduras tem sobre a ressonância do enquadramento. Essa preocupaçáo do FBI também leva a uma segunda hipótese importante, a de que o Estado tem como desvantagem na disputa pela supremacia cultural a constante necessidade de renovação de sua legitimidade perante os cidadáos (NOAKES, 2005).

O principal problema visível tanto no trabalho de Walgrave e Manssens (2005) quanto no trabalho de Noakes (2005) está relacionado à dificuldade de generalizaçáo das propostas teóricas em decorrência dos desenhos de pesquisa baseados em estudos de caso. ${ }^{7}$ Os autores reconhecem, por exemplo, que a grande mídia e o Estado tendem a adotar essa postura apenas em casos excepcionais. Observa-se, assim, a necessidade de construçáo de novas pesquisas empíricas que analisem em quais casos esses atores incentivam a mobilização coletiva, investigando-se, por exemplo, quais tipos de veículos de comunicaçáo e governos com quais tipos de orientaçáo ideológica estáo mais dispostos a adotar essa postura ou que tipos de molduras interpretativas sấo potencialmente mais apoiados por esses atores. Outro tema náo analisado pelos pesquisadores é a intencionalidade ${ }^{8}$ desses atores em mobilizar processos contestatórios. A análise dessa problemática pode trazer reflexóes importantes sobre como a construçáo de novos sentidos para a mobilizaçáo coletiva por parte do Estado e da grande mídia pode ser utilizada como ferramenta para a desmobilizaçáo de processos contestatórios em curso ou sobre como o incentivo à açáo coletiva por grandes veículos de comunicaçáo pode ser utilizado como uma ferramenta para criar ou reforçar a oposição a governos estabelecidos.

Outro debate em pauta é a relaçáo entre enquadramento interpretativo e EOPs. ${ }^{9}$ A literatura contemporânea enfatiza a existência de uma relaçáo de influência mútua entre essas duas dimensóes da açáo coletiva (NOAKES; JOHNSTON, 2005). Na coletânea analisada, dois artigos abordam essa relaçáo, cada uma enfatizando uma direçáo de influência entre esses elementos. Kenney (2005) defende que a forma como movimentos sociais definem as atividades do Estado pode afetar diretamente a EOP, modificando-a em favor

7 Essa deficiência metodológica também é apontada por Bandy (2006) em sua análise dessa coletânea.

8 O exame das intenções dos atores é uma das dimensões propostas por Johnston (2005), nessa mesma coletânea, em sua metodologia para uma análise de molduras.

9 Como exemplos de estudos relacionados a esse debate, podem ser citados os trabalhos de Diani (1996) Kurzman (1996) e Stanbridge (2002) 
dos militantes. Esse autor argumenta que, quando movimentos sociais têm sucesso em difundir a interpretação de que a repressão policial é injusta e ultrajante, ameaçam aquilo que Noakes (2005) em seu artigo demonstra ser fundamental para o Estado, a sua legitimidade. Dessa forma, o enquadramento proposto por ativistas pode levar a uma diminuiçáo da repressáo e, portanto, à modificaçáo da EOP. De forma alternativa, militantes podem se adaptar estrategicamente às características estruturais. Schneider (2005), por exemplo, defende que grupos de imigrantes porto-riquenhos habitantes de diferentes bairros de Nova Iorque adotam distintas estratégias de enquadramento que váo ao encontro das características do contexto político local no intuito de obter maior ressonância para suas molduras. Por meio dessa adaptaçáo estratégica, portanto, a EOP pode afetar diretamente os processos de enquadramento interpretativo. Nenhum dos estudos, no entanto, sistematiza em uma mesma análise a sequência de mecanismos de influência mútua entre essas duas dimensóes, focando-se ora na influência das Miacs sobre as EOPs e ora na influência das EOPs sobre as Miacs, sem integrar essas duas direçóes de influência. Essa integração diacrônica da análise pode, por exemplo, contribuir para uma discussão mais aprofundada sobre como aspectos políticos estruturais e simbólicos em interaçáo influenciam a formataçáo de ciclos de protestos, como propóe Tarrow (2009).

O último grande debate tratado nessa coletânea se estabelece em torno da problemática da construçáo de Miacs. A análise desse fenômeno pode ser dividida em dois temas: a busca pelas categorias que dáo origem às Miacs; e o exame das características dos processos de enquadramento.

Noakes e Johnston (2005) expóem a tese central dessa abordagem acerca do primeiro desses temas baseadas na proposta teórica de Swidler (1986): a cultura vigente é uma "caixa de ferramentas" da qual movimentos sociais retiram símbolos para construir mensagens de mobilizaçáo. $\mathrm{O}$ artigo de Valocchi (2005) aponta uma resposta mais específica do que essa tese a essa problemática. ${ }^{10} \mathrm{O}$ autor examina os diversos enquadramentos presentes na emergência do movimento de libertação gay nos Estados Unidos entre os anos de 1969 e 1973. Segundo o autor, cada "corrente" desse movimento

10 Outra resposta mais específica a esse problema é proposta por Tarrow (1992), que busca a origem das Miacs na "cultura politica" e nas "mentalidades sociais". 
constrói seu enquadramento a partir da referência a distintos movimentos que o precederam, assim como a partir do compartilhamento de símbolos com distintos movimentos sociais em atividade na mesma época. Assim, duas fontes de símbolos sáo identificadas: as Miacs de movimentos precedentes e as Miacs de movimentos aliados. Esse autor enfatiza, ainda, que essas diversas fontes de símbolos podem ser a origem de conflitos internos entre organizaçóes de um mesmo movimento social. $\mathrm{O}$ trabalho desse autor, no entanto, apresenta limitaçóes, na medida em que as fontes de elementos simbólicos por ele apontadas náo parecem cumprir a tarefa de fornecimento de símbolos de contestaçáo inovadores por parte de movimentos sociais. O surgimento de inovaçóes interpretativas ocorreria, de acordo com a proposta desse autor, apenas por meio de novas combinaçōes entre símbolos já utilizados em situações de confronto político, não sendo apontados elementos "exógenos" a situaçóes de conflito que posam ser re-significados por parte de ativistas de movimentos sociais e incorporados à sua luta.

Por fim, a outra grande temática de discussão dessa literatura no que tange à construçáo de Miacs é a análise das características dos processos de enquadramento. As dificuldades de se lidar com esse problema parecem estar conectadas a grande parte das disputas teóricas entre autores apresentadas na última sessão do livro, assim como a um dos mais importantes debates estabelecidos dentro dessa abordagem: a tensão entre o "estratégico", o "intencional" e o "ideológico"."

Em sua revisáo bibliográfica publicada em um momento anterior à coletânea de artigos aqui analisada, Benford e Snow (2000) propóem diferentes tipos de processos de enquadramento responsáveis pela produçáo das Miacs. Os processos discursivos seriam aqueles conduzidos de forma cotidiana pelos militantes em encontros náo necessariamente ligados a discussóes políticas. Esses processos ocorrem de forma tácita, sem um planejamento prévio por parte dos ativistas. Já os processos estratégicos de enquadramento interpretativo teriam como característica o exame cuidadoso das consequências das mensagens mobilizadas pelo movimento social para a conquista de seus objetivos, tipo de processo ao qual os trabalhos produzidos por esses autores ao longo da década

II Como exemplos de estudos relacionados a esse debate, podem ser citados os trabalhos de Gillan (2008), Maia (2009), Mendonça e Simões (2012), Steinberg (1998) e Snow e Benford (1988). 
de $1980^{12}$ foram dedicados. Noakes e Johnston (2005) identificam esse viés inicial da literatura do enquadramento interpretativo e associam ao conceito de Miac apenas uma dimensão "estratégica" em sua revisão bibliográfica. ${ }^{13}$

Para analisar a dimensáo "náo estratégica" dos fenômenos interpretativos, Oliver e Johnston (2005) propóem o resgate do conceito de ideologia. Segundo os autores, molduras interpretativas, quando aplicadas ao estudo de movimentos sociais, "se referem, na maior parte, à atividade intencional de empreendedores de movimentos no nível organizacional" (OLIVER; JOHNSTON, 2005, p. 193, traduçáo livre). Elas estariam ligadas ao raciocínio e à lógica de marketing adotada pelos movimentos em determinadas situaçóes. Já o conceito de ideologia focaria a atençáo nos "sistemas de crenças como um todo, em suas múltiplas dimensóes, e em como as ideias estão relacionadas umas as outras" (OLIVER; JOHNSTON, 2005, p. 194, tradução livre), referindo-se a uma dimensáo construcionista de pensamento e à relaçáo de ensino e aprendizagem estabelecida entre ativistas e potenciais aderentes.

Snow e Benford (2005), no entanto, discordam dessa definição conceitual. Segundo esses autores, o conceito de enquadramento interpretativo teria também um aspecto construcionista e de aprendizado social. Essa dimensão parece ser contemplada por meio do conceito de "processos discursivos" proposto por esses mesmos autores anteriormente (BENFORD; SNOW, 2000). Esses estudiosos defendem que a diferença entre os conceitos de ideologia e molduras interpretativas é a dinamicidade desses processos de interpretaçáo. Ideologias seriam interpretaçóes mais fixas, sendo fontes para os processos de enquadramento. Já o conceito de Miac responderia à vulnerabilidade do conceito de ideologia à reificação, enfatizando a dinamicidade dos processos estratégicos, de negociaçáo de sentido e de aprendizado social existentes em interaçóes cotidianas.

Em suma, percebe-se uma grande indefinição teórica no que tange a questóes interpretativas "náo estratégicas" por parte da abordagem do enquadramento

12 Destaca-se, nesse sentido, o artigo clássico de Snow et al. (1986) sobre os processos de alinhamento de molduras.

13 Se a análise de que a literatura do enquadramento interpretativo é demasiadamente "estratégica" é pertinente no que se refere à produção inicial de Benford e Snow (como admitido pelos próprios autores), ela não se mostra capaz de captar as reformulações teóricas propostas por esses autores, como no texto de Benford (1997) e de Benford e Snow (2000). 
interpretativo que náo é superada pelos artigos expostos nessa coletânea. Se Oliver e Johnston (2005) associam esse pensamento "não estratégico" ao conceito de ideologias, Snow e Benford (2005) buscam manter essa característica dentro do conceito de Miac por meio da dimensáo discursiva dos processos de enquadramento. Ainda, a definiçáo de o que é "não estratégico" não parece náo ser compartilhada pelas duas propostas conceituais. O conceito de ideologia de Oliver e Johnston (2005) associa a ideia de "náo estratégico" a teorias e convicçóes dos atores acerca da sociedade, que guiam as atividades dos movimentos sociais e que são pouco negociáveis de acordo com as exigências estratégicas das situaçóes. Nesse caso, estabelece-se uma tensáo entre o "ideológico" e o "estratégico". Já o conceito de processos discursivos de Benford e Snow (2000) associa o termo "náo estratégico" ao enquadramento que náo foi submetido a um "cálculo" de efetividade para a obtençáo de um objetivo. Nesse caso, estabelece-se uma tensão entre o "estratégico e intencional" e o "tácito e não intencional".

Apesar de não apresentar soluçóes consensuais para essas indefiniçóes conceituais, a coletânea em análise apresenta novas contribuiçóes para esse debate. O artigo de Westby (2005), por exemplo, propóe uma análise de como ideologia e imperativo estratégico podem se combinar nos processos de enquadramento interpretativo de movimentos sociais. Segundo o autor, nesses processos há uma relação tensa entre os significados partilhados pelos ativistas que sáo importantes para a organizaçáo de sua experiência (a ideologia) e a exigência estratégica de que movimentos moldem seus argumentos de acordo com as características das interaçóes (o imperativo estratégico). Essa relaçáo tensa dá origem a diversas combinaçóes que valorizem mais ou menos cada um desses elementos. Nesse artigo, porém, a confusáo conceitual fica ainda mais clara. Se, inicialmente, o autor adota a divisão conceitual entre "ideologia" e "enquadramento interpretativo" de Oliver e Johnston (2005), ao longo do texto, o autor defende que "ideologia" e "imperativo estratégico" são dimensóes competitivas dos processos de enquadramento interpretativo de forma análoga ao que Benford e Snow (2000) propóem.

Essa falta de clareza nas delimitaçôes conceituais expóe as fragilidades teóricas que ainda devem ser superadas por essa abordagem. As dificuldades encontradas nesse debate parecem estar associadas a fragilidades observáveis nas dicotomias estabelecidas, em muitos casos, pela utilizaçáo do conceito de 
"estratégia". Como destaca Polletta (1997), a literatura tende a estabelecer antagonismos entre os comprometimentos normativos dos atores (sua ideologia) e a adaptaçáo "racional" dos sujeitos às exigências das situaçóes (a estratégia), ignorando que as próprias convicçóes ideológicas dos atores formam sua definição de qual é uma "boa estratégia" de ação. Dessa forma, esses elementos náo podem ser vistos como polos antagônicos de uma dicotomia, mas antes como dimensóes complementares dos processos de atribuiçáo de sentido (POLLETTA, 1997).

Por fim, outros dois artigos dessa coletânea respondem a críticas comuns dirigidas a essa abordagem: a negligência em relaçáo às emoçóes (GOODWIN; JASPER; POLETTA, 2001) e a falta de rigor metodológico (BENFORD, 1997). Cadena-Roa (2005) analisa como representaçóes teatrais de combates na cidade do México protagonizadas pelo herói "Superbarrio" (Super Bairro) suscitam duas fortes emoçóes em uma populaçáo que sofre ameaças de remoçáo do centro para a periferia da cidade: a indignaçáo frente à injustiça e a esperança. Teoricamente, esse autor constrói um conceito de "emoção" de forma não dicotômica ao conceito de "razáo". Ambos os elementos são vistos como formas complementares e náo hierárquicas de conhecimento do mundo. No caso em estudo, noçóes cognitivas (como a de injustiça) e emoçôes (como a indignaçáo) seriam partes do enquadramento que tornou esse lutador um símbolo nacional de resistência. Uma sistematização teórica aprofundada sobre a relaçáo entre emoçóes e Miacs, no entanto, náo é apresentada.

Já Johnston (2005), no capítulo final dessa coletânea, faz uma reflexão metodológica profunda, propondo uma análise comparada de molduras interpretativas. Segundo esse autor, a partir de textos e falas dos militantes, os pesquisadores deveriam reconstruir a estrutura de pensamento que originou o discurso por meio da identificaçáo dos componentes da fala e da sua organizaçáo em uma estrutura hierárquica que os correlacione. ${ }^{14}$ Esse esquema hierárquico das ideias deve, ainda, indicar a fonte empírica na qual cada componente foi identificado, permitindo comparaçóes futuras. O pressuposto dessa abordagem é o de que molduras interpretativas são estruturas cognitivas

14 Essa construção deve orientar-se por cinco principios: a análise do contexto em que a fala se insere; a intenção pragmática dos atores com a fala; o papel social assumido pelos atores na fala; a análise do texto em sua totalidade; $e$ a atenção a dicas não verbais, tais como expressões faciais e mudanças no tom de voz (JOHNSTON, 2005). 
que, apesar de terem uma origem social, estáo inseridas nas mentes dos indivíduos. Snow e Benford (2005) se opóem a essa visão, defendendo que o enquadramento é um processo interpretativo atrelado a interaçóes sociais. A proposta metodológica de Johnston (2005) negligenciaria, portanto, o caráter processual que esse conceito enfatiza. Snow e Benford (2005), no entanto, não apresentam uma proposta metodológica detalhada para a análise dos processos interativos de negociaçáo de sentido. Em resposta a essas críticas, Johnston (2005) reconhece o problema em sua proposta, mas sustenta que opta deliberadamente por um "método prático" que valorize a precisão na produçáo dos dados (permitindo a comparaçáo), em detrimento da análise da complexidade da realidade social. Dessa forma, a coletânea não apresenta uma proposta metodológica capaz de aliar a análise dos processos interativos de negociaçáo de sentido à análise comparativa de molduras, seja ela efetuada de forma diacrônica, como propóe Johnston (2005), seja ela efetuada de forma sincrônica, comparando-se as molduras de diversos movimentos sociais ou de diversas organizaçóes de um mesmo movimento social.

Em suma, a coletânea Frames of protest exibe ao leitor os principais debates estabelecidos em torno da abordagem do enquadramento interpretativo, assim como os desafios que persistem nessa literatura. Por um lado, sáo apresentadas novas reflexóes sobre: o fenômeno da ressonância do enquadramento interpretativo; a construçáo das Miacs; o papel ativo de outros atores inseridos no contexto de confronto político na construção de significados; e a relação entre Miacs e EOPs. Por outro lado, essas contribuiçóes deixam lacunas a serem exploradas empiricamente por estudiosos da ação coletiva, como: as formas pelas quais diferentes objetivos estabelecidos para a açáo coletiva influenciam as dinâmicas e os resultados do enquadramento interpretativo; as intençóes de atores como a mídia e o Estado, que os estimulam a construir mensagens que incentivem a açáo coletiva; a origem de elementos interpretativos inovadores na construção de Miacs; e a complexa relaçáo entre emoçôes e enquadramento interpretativo. Ainda, os debates teóricos e metodológicos apresentados nessa coletânea náo sáo capazes de oferecer soluçóes para indefiniçóes e fragilidades presentes nessa abordagem. Nesse sentido, observa-se um intenso campo de debates em aberto para que estudiosos brasileiros nele se insiram, discutindo como o estudo das dinâmicas contestatórias nacionais e latino-americanas pode contribuir para o aprofundamento das reflexóes teóricas em curso e para a identificaçáo de limites dessa abordagem. 


\section{Referências}

AUYERO, J. Vidas e política das pessoas pobres: as coisas que um etnógrafo político sabe (e não sabe) após 15 anos de trabalho de campo. Sociologias, ano 13, n. 28, p. 126-164, 2011.

BABB, S. "A true american system of finance": frame resonance in the U.S. labor movement, 1866 to 1886. American Sociological Review, v. 61, n. 6, p. 1.033-1.052, 1996.

BENFORD, R. D. An insider's critique of the social movement framing perspective. Sociological Inquiry, v. 67, n. 4, p. 409-430, 1997.

; SNOW, D. A. Framing processes and social movements: an overview and assessment. Annual Review of Sociology, n. 26, p. 611-639, Aug. 2000.

BERTONCELO, E. R. E. "Eu quero votar para presidente": uma análise sobre a Campanha das Diretas. Lua Nova, Sáo Paulo, n. 76, p. 169-196, 2009.

CADENA-ROA, J. Strategic framing, emotions, and supebario - Mexico's City's masked crusader. In: JOHNSTON, H.; NOAKES, J. A. (Org.). Frames of protest: social movements and the framing perspective. Lanham: Rowman \& Littlefield Publishers, 2005. p. 69-86.

DIANI, M. Linking mobilization frames and political opportunities: insights from regional populism in Italy. American Sociological Review, v. 61, n. 6, p. 1.053-1.069, 1996.

GAMSON, W.; FIREMAN, B.; RYTINA, S. Encounters with Unjust Authorities. Illinois: The Dorsey Press, 1982.

GILLAN, K. Understanding meaning in movements: a hermeneutic approach to frames and ideologies. Social Movement Studies, v. 7, n. 3, p. 247-263, 2008.

GIUGNI, M. G.; MCADAM, D.; TILLY, C. (Org.). How social movements matter. Minneapolis, London: University of Minnesota Press, 1999.

GOFFMAN, E. Frame analysis: an essay on the organization of experience. Boston: Northeastern University Press, 1986.

GOODWIN, J.; JASPER, J. M.; POLLETTA, F. (Org.). Passionate politics: emotions and social movements. Chicago: The University of Chicago Press, 2001.

HEWITT, L.; MCCAMMON, H. Explaining suffrage mobilization: balance, neutralization, and range in collective action frames. In: JOHNSTON, H.; NOAKES, J. A. (Org.). Frames of protest: social movements and the framing perspective. Lanham: Rowman \& Littlefield Publishers, 2005. p. 33-52.

JOHNSTON, H. Comparative frame analyses. In: JOHNSTON, H.; NOAKES, J. A. Frames of protest: social movements and the framing perspective. Lanham: Rowman \& Littlefield Publishers, 2005. p. 237-260. 
Molduras do protesto: debates e desafios da abordagem do enquadramento interpretativo no estudo de movimentos sociais | Matheus Mazzilli Pereira

; NOAKES, J. A. (Org.). Frames of protest: social movements and the framing perspective. Lanham: Rowman \& Littlefield Publishers, 2005.

; NOAKES, J. A. (Org.). Frames of protest: social movements and the framing perspective. Lanham: Rowman \& Littlefield Publishers, 2005. Resenha de: BANDY, Joe. Social Forces, v. 85, n. 2, p. 1.049-1.051, 2006.

; ALIMI, E. Y. Primary frameworks, keying and the dynamics of contentious politics: the islamization of the Chechen and Palestinian National Movements. Political Studies, v. 60, n.3, p. 603-620, Oct. 2012.

; ALIMI, E. Y. A methodology analyzing for frame dynamics: the grammar of keying battles in palestian nationalism. Mobilization: An International Quarterly, v. 18, n. 4, p. 453-474, 2013. KENNEY, P. Framing, political opportunities, and East European mobilization. In: JOHNSTON, H.; NOAKES, J. A. (Org.). Frames of protest: social movements and the framing perspective. Lanham: Rowman \& Littlefield Publishers, 2005. p. 143-161.

KURZMAN, C. Structural opportunity and perceived opportunity in social-movement theory: the Iranian revolution of 1979. American Sociological Review, v. 61, p. 153-170, 1996.

MACIEL, D. A. Açáo coletiva, mobilização do direito e instituiçóes políticas: o caso da Campanha da Lei Maria da Penha. Revista Brasileira de Ciências Sociais, v. 26, n. 77, p. 97-111, 2011.

MAIA, R. Atores da sociedade civil e açáo coletiva: relaçóes com a comunicaçáo de massa. Lua Nova, n. 76, p. 87-118, 2009.

MCADAM, D. Marcos interpretativos y tácticas utilizadas por los movimientos: dramaturgia estratégica en el Movimiento Americano Pro-Derechos Civiles. In: ; MCCARTHY, J. D.; ZALD, M. N. (Org.). Movimientos sociales - perspectivas comparadas: oportunidades políticas, estructuras de movilización y marcos interpretativos culturales. Madrid: Istmo, 1999. p. 475-496.

; MCCARTHY, J. D.; ZALD, M. N. (Org.). Movimientos sociales - perspectivas comparadas: oportunidades políticas, estructuras de movilización y marcos interpretativos culturales. Madrid: Istmo, 1999.

MENDONÇA, R. F.; SIMÓES, P. G. Enquadramento: diferentes operacionalizaçóes analíticas de um conceito. Revista Brasileira de Ciências Sociais, v. 27, n. 79, p. 187-201, 2012.

NOAKES, J. A. Official frames in social movement theory: the FBI, HUAC and the communist threat in Hollywood. In: JOHNSTON, H.; NOAKES, J. A. (Org.). Frames of protest: social movements and the framing perspective. Lanham: Rowman \& Littlefield Publishers, 2005. p. 89-111. 
; JOHNSTON, H. Frames of protest: a road map to a perspective. In: JOHNSTON, H.; NOAKES, J. A. (Org.). Frames of protest: social movements and the framing perspective. Lanham: Rowman \& Littlefield Publishers, 2005. p. 1-29.

OLIVER, P. E.; JOHNSTON, H. What a good idea! Ideologies and frames in social movement research. In: JOHNSTON, H.; NOAKES, J. A. (Org.). Frames of protest: social movements and the framing perspective. Lanham: Rowman \& Littlefield Publishers, 2005. p. 185-203.

POLLETTA, F. Culture and its discontents: recent theorizing on the cultural dimensions of protest. Sociologial Inquiry, v. 67, n. 4, p. 431-450, 1997.

PRUDENCIO, K. C. S.; SANTOS, J. J. Mídia e movimentos sociais: um esboço metodológico a partir da frame analysis de Erving Goffman. In: ENCONTRO DA COMPOLÍTICA, 4., 2011, Rio de Janeiro. Anais... Rio de Janeiro, 13 a 15 de abril de 2011. Disponível em: < http://www.compolitica. org/home/wp-content/uploads/2011/03/Kelly-Prudencio.pdf>. Acesso em: 15 jan. 2014.

QUIRÓS, J. Política e economia na ação coletiva: uma crítica etnográfica às premissas dicotômicas. Mana, v. 15, n. 1, p. 127-153, 2009.

SCHNEIDER, C. Political opportunities and framing Puerto Rican identity in New York City. In: JOHNSTON, H.; NOAKES, J. A. (Org.). Frames of protest: social movements and the framing perspective. Lanham: Rowman \& Littlefield Publishers, 2005. p. 163-181.

SILVA, M. K. De volta aos movimentos sociais? Reflexóes a partir da literatura brasileira recente. Ciências Sociais Unisinos, v. 1, n. 46, p. 2-9, 2010.

SNOW, D. A. et al. Frame alignment processes, micromobilization, and movement participation. American Sociological Review, v. 51, n. 4, p. 464-481, 1986.

; BENFORD, R. D. Ideology, frame ressonance and participant mobilization. International Social Movements Research, n.1, p. 197-218, 1988.

; BENFORD, R. D. Clarifying the relationship between framing and ideology. In: JOHNSTON, H.; NOAKES, J. A. (Org.). Frames of protest: social movements and the framing perspective. Lanham: Rowman \& Littlefield Publishers, 2005. p. 205-211.

STANBRIDGE, K. Master frames, political opportunities, and self-determination: the Asland Islands in the post-WWI period. The Sociological Quaterly, v. 43, n. 4, p. 527-552, 2002.

STEINBERG, M. W. Tilting the frame: considerations on collective action framing from a discursive turn. Theory and Society, n. 27, p. 845-872, 1998. 
Molduras do protesto: debates e desafios da abordagem do enquadramento interpretativo no estudo de movimentos sociais | Matheus Mazzilli Pereira

TARROW, S. Mentalities, politial cultures, and collective action frame: constructing meanings through action. In: MORRIS, A. D.; MUELLER, C. M. Frontiers in social movement theory. New York: Yale University, 1992. p. 174-202.

Poder em movimento: movimentos sociais e confronto político. Petrópolis, RJ: Vozes, 2009.

SWIDLER, A. Culture in action: symbols and strategies. American Sociological Review, v. 51, n. 2, p. 273-286, 1986.

VALOCCHI, S. Collective action frames in the Gay Liberation Movement, 1969-1973. In: JOHNSTON, H.; NOAKES, J. A. (Org.). Frames of protest: social movements and the framing perspective. Lanham: Rowman \& Littlefield Publishers, 2005. p. 53-67.

WALGRAVE, S.; MANSSENS, J. Mobilizing the White March: media frames as alternatives to movement organizations. In: JOHNSTON, H.; NOAKES, J. A. (Org.). Frames of protest: social movements and the framing perspective. Lanham: Rowman \& Littlefield Publishers, 2005. p. 113-140.

WESTBY, D. L. Strategic imperative, ideology and frames. In: JOHNSTON, H.; NOAKES, J. A. (Org.). Frames of protest: social movements and the framing perspective. Lanham: Rowman \& Littlefield Publishers, 2005. p. 217-235.

Recebido em: 19/07/2013

Aprovado em: 15/03/2014

\section{Frames of protest: debates and challenges to the interpretative framing for the study of social movements}

\section{Abstract}

This bibliographic essay aims present the main debates established in the framing perspective applied to the social movement studies, since the Brazilian studies on this area only recently dedicate attention to this framework already established in other countries. Following this intention, it is proposed an analysis of the paper selection edited by Hank Johnston and John A. Noakes, entitled Frames of protest. This book gathers several papers that present important theoretical contributions to the already established debates in this field of studies. Nevertheless, the studies presented in this paper selection leave new questions unanswered and seem insufficient to overcome the problems of conceptual indefiniteness and methodological fragilities faced by this perspective.

Keywords: Collective action sociology. Framing. Collective action frames. 